\title{
LA MAISON CACHÉE DE LE CORBUSIER. HÁBITAT Y HABITAR EN RUE JACOB, 1917-1934
}

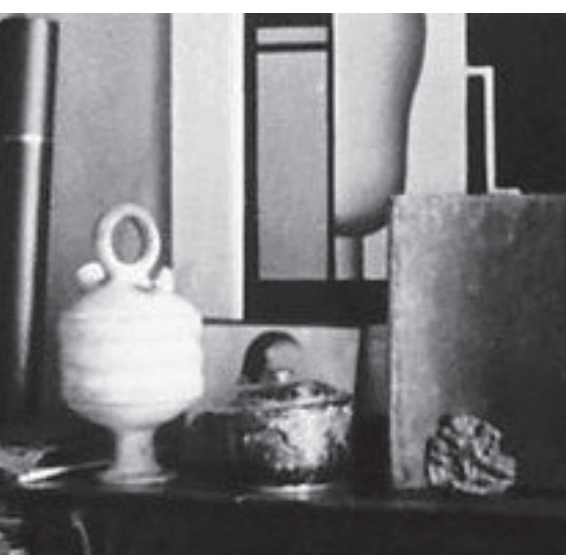

José Ramón Alonso Pereira

Le Corbusier's maison cachée. Habitat and living on rue Jacob, 1917-1934

Boletín Académico. Revista de investigación y arquitectura contemporánea

Escuela Técnica Superior de Arquitectura. Universidade da Coruña

elSSN 2173-6723

unw.boletinacademico.com

Número 4 (2014)

Páginas 13-22

Fecha de recepción 24.10.2013

Fecha de aceptación 13.01.2014

https://doi.org/10.17979/bac.2014.4.0.1005

\section{Resumen}

Edificado en condiciones de Ville Radieuse — según expresión de Le Cor-busier-, Porte Molitor ha sido siempre considerado el hábitat corbuseriano por excelencia. Ello ha oscurecido otro lugar donde vivió diecisiete largos y fecundos años: la casaapartamento junto a Saint Germain, donde residió entre 1917 y 1934. Es el hábitat desconocido: la maison cachée de Le Corbusier. Esta monografía pretende analizar esta casa escondida en su doble aspecto del hábitat y del habitar. Descubrir el lugar y el espacio donde Le Corbusier vivía y su modo de habitarlo, haciendo de la maison cachée un antecedente del hábitat radieuse.

\begin{abstract}
Built in Ville Radieuse's conditions — as Le Corbusier used to say-, Porte Molitor has been ever considered the corbuserian habitat for excellence. This has darked another place where he lived for 17 long and fertile years: the appartament besides Saint Germain, where he resides between 1917 and 1934. It is the unknown habitat: the maison cachée of Le Corbusier. This paper tries to analyse this hide home on the double aspect of habitat and inhabit. To discover the place and the space where Le Corbusier lived and the way he lived in, looking this maison cachée as an antecedent of the radieuse living.
\end{abstract}

\section{Palabras clave}

Le Corbusier, hábitat, habitar, París, Ville Radieuse, arquitectura del siglo XX

\section{Keywords}

Le Corbusier, Habitat, Inhabit, Paris, Ville Radieuse, XX century Architecture 

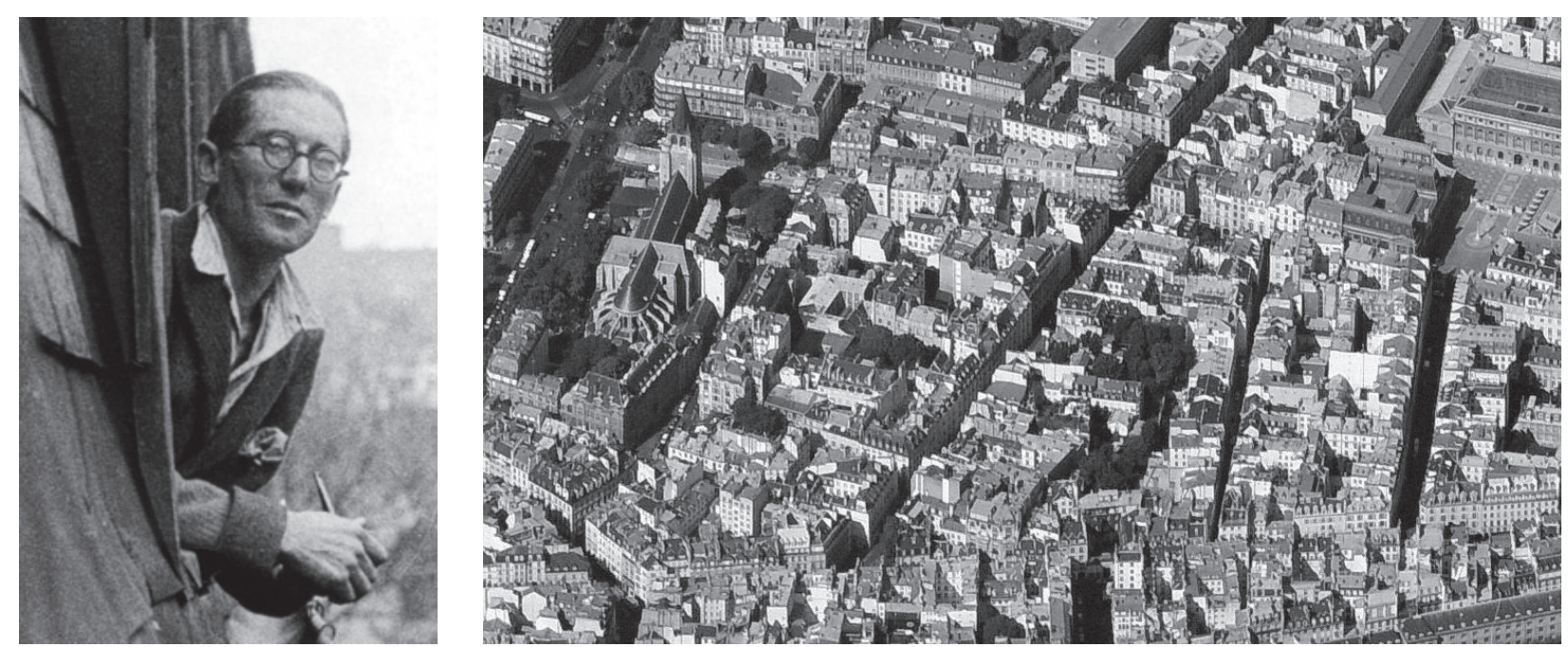

$\mathbf{0 1}$ Le Corbusier en rue Jacob, h. 1920

02 Foto aérea del barrio de Saint Germain des Près, donde se aprecia el espléndido jardín interior de la manzana Visconti-Jacob.

\section{LE CORBUSIER Y PARÍS}

La casa-apartamento en rue Jacob junto a Saint Germain, donde Le Corbusier residió casi dos décadas entre 1917 y 1934, es un hábitat casi desconocido: una maison cachée .

La Corbusier se instaló en París a lo largo de 1917. Había descubierto la ciudad en 1908-1909 en una larga estancia de estudio y trabajo ${ }^{2}$, desarrollado éste en el estudio de Perret, a quien ya en 1912 le confesaría cuánto echaba de menos la ciudad: «Me muero de pena por París. Me sería como el agua que, pobre pez, desearía en mi boca. Estambul para los ojos, América para el espíritu, las Islas para los sentidos, pero para vivir, París» ${ }^{3}$. La instalación no se hizo de una sola vez. Doce meses después de estallar la Guerra Europea, estuvo siete semanas para acabar los estudios urbanísticos de La Construction des Villes y poner en marcha su sistema Domino con Max du Bois, alojándose en la casa de éste junto al Trocadero ${ }^{4}$. Volvió dos semanas en 1916, alojándose esta vez frente al Louvre, en el Hotel Quai Voltaire, donde habían estado sus padres en $1909^{5}$.

En 1917 los viajes se multiplicaron. En enero marchó de nuevo a París. En febrero regresó para organizar su oficina y alquiló un apartamento en Jacob, a medio camino entre Quai Voltaire y Saint Germain (Fig. 01). Volvió en marzo, en junio y en septiembre. ¿¿Eran estancias en París con frecuentes viajes a La Chaux, o estancias en La Chaux con viajes frecuentes a París? La situación se resolvió a comienzos de otońo, al cerrar su oficina suiza. El 6 de octubre, día en que cumplía los 30 años, su padre anotó en su diario: «Édouard acaba de dejar definitivamente La Chaux y se establece fijo en París» ${ }^{6}$.

\section{PARÍS RIVE DROITE, PARÍS RIVE GAUCHE}

El París de esa época puede definirse a través del contraste social, cultural y urbano entre dos orillas, que se oponen dialécticamente entre sí. La orilla derecha, la Rive Droite, es el París de las finanzas, el comercio, el lujo y el espectáculo; el París trepidante y agitado. La orilla izquierda, la Rive Gauche, es el París cultural y universitario, el de la bohemia y las vanguardias, donde los lugares de ocio se ligan a los de creación cultural y artística.

La vida de Le Corbusier bascula en esos años entre la Rive Gauche, donde reside, y la Rive Droite, donde están sus oficinas y donde alojará las de L'Esprit Nouveau. En 1917 dice a su hermano: «Todo va bien. Du Bois me es un apoyo seguro en la Rive Droite, y en la Rive Gauche me las arreglo yo solo, encontrando ahí todo el ambiente deseable»? La dislocación entre trabajo y residencia refleja la oposición que muestran entonces ambas orillas.

Fueron varios los intentos de resolver esa dualidad, primando una de ellas. En los primeros ańos parece que iba a ser la Rive Droite la escogida. Así en enero de 1919 dice a sus padres: «Pienso conservar mi apartamento en Jacob», pero tan sólo para recibir a la familia o a los amigos, o sea, como hôtelerie, pues «busco alo- 


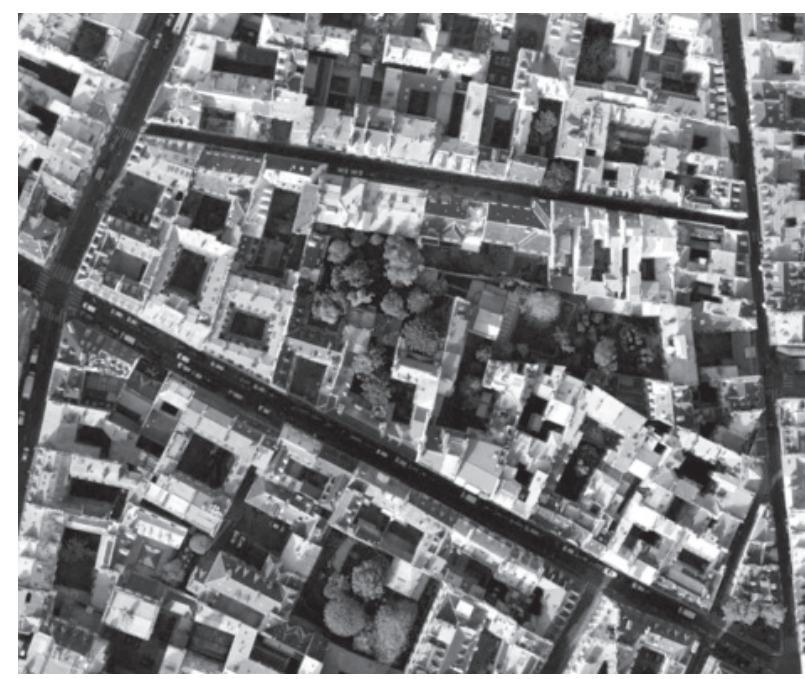

$0 \mathbf{0 3}$ Ortofoto de la manzana Visconti-Jacob.

04 La manzana Visconti-Jacob en el catastro Verniquet (s. XVIII).

jarme cerca de mis negocios. He roto moralmente con la Rive Gauche» ${ }^{8}$. En mayo, animando a su hermano a instalarse en París, le ofrece su apartamento en Jacob, porque - le indica - «yo me mudo al centro, a la otra orilla»". Busca una situación ideal a dos pasos de su oficina, que le permitiera resolver la contradicción entre vivienda y trabajo. Pocos años después la opción cambia y es la Rive Gauche la seleccionada de forma definitiva.

Más que razones sociales o profesionales, en ese cambio sustancial priman las razones personales. En 1922 conoce a Yvonne, Jeanne-Victorine Gallis (1892-1957), modelo monegasca que se convertirá en su esposa. Desde ese verano comparte su domicilio con ella, cuya presencia se iría consolidando en su vida. Jacob fue desde entonces no sólo el refugio doméstico sino también el centro de la vida social cotidiana de ambos.

Ese mismo año 1922 se había asociado con su primo Pierre Jeanneret (1896-1967), con quien construye el atelier Ozenfant; estudia la casa Citrohan y los Inmuebles-villas, y presenta la Ville Contemporaine. Tras siete años de dualidad entre Rive Droite y Rive Gauche, en 1924 mueve su estudio a rue de Sèvres ${ }^{10}$. Desde ese momento la Rive Gauche, sin dejar de ser lugar de residencia, se convierte también en lugar de su actividad pública y profesional.

\section{LE CORBUSIER Y LA RIVE GAUCHE}

En esos años la Rive Gauche es un lugar de encuentro de las élites intelectuales y artísticas de París. Su emblema son los barrios de Saint Germain y Montparnasse (Fig. 02).

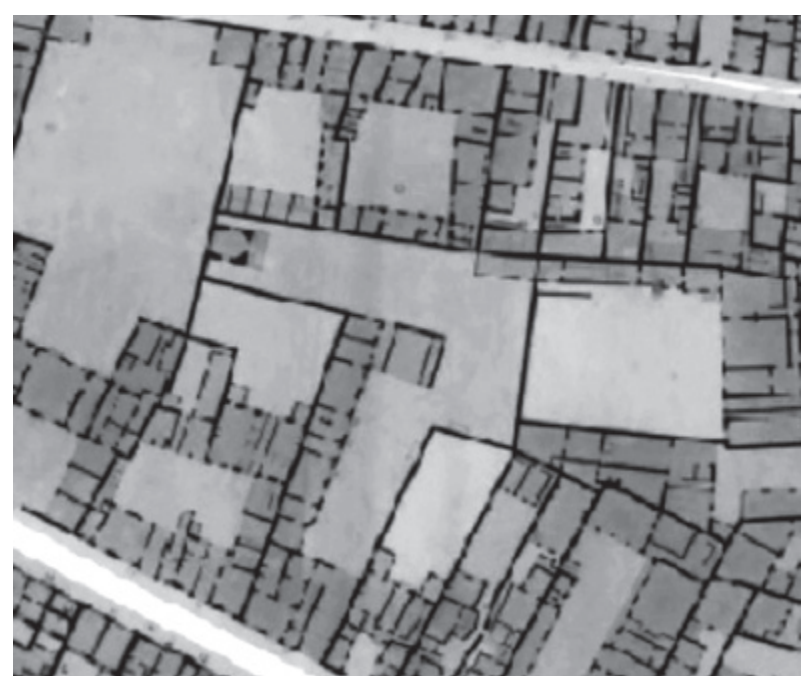

Saint Germain des Près — dijo Farge- «es la mejor plaza para estar a la escucha del mundo» ${ }^{11}$. Convertida en uno de los sitios más vivos de París, la plaza era un carrefour de vías, oficios y opiniones. En los años veinte y treinta acogía un público diverso, donde se mezclaban artistas y escritores: Apolinaire, Breton, Gide, Giraudoux, Saint-Exupery, Zweig, Man Ray, Arp o Le Corbusier ${ }^{12}$.

Al sur de Saint Germain se sitúa Montparnasse, donde se instalan en estos años artistas y escritores de todas las naciones, haciendo de París la capital de las vanguardias.

Al norte, los artistas ocupan también la parte inmediata a la École des Beaux-Arts. Una zona cuyas calles estaban bordeadas de viejas casas donde podían alquilarse apartamentos modestos, con vastas cocheras y cuadras, transformadas en atelier de artistas.

En ese barrio entre Saint Germain y el Instituto, las calles eran estrechas, pero sus casas se abrían a jardines interiores, casi parques de manzana. Particularizando el barrio en Visconti, Champion escribió: «Está orientada de este a oeste, atravesada en su centro por la línea ideal del meridiano de París. La luz penetra a través de las brumas de la mañana o las luces de la tarde (...) Fría, noble y sórdida a la vez (es) un canal donde flotan los sueños» ${ }^{13}$.

La calle Jacob estaba en el corazón del barrio (Fig. 03). Paralela a Visconti, aunque con mayor anchura y longitud, bordeaba el antiguo foso de la abadía de Saint Germain, yendo de Seine a Saintes Pères. La vía 


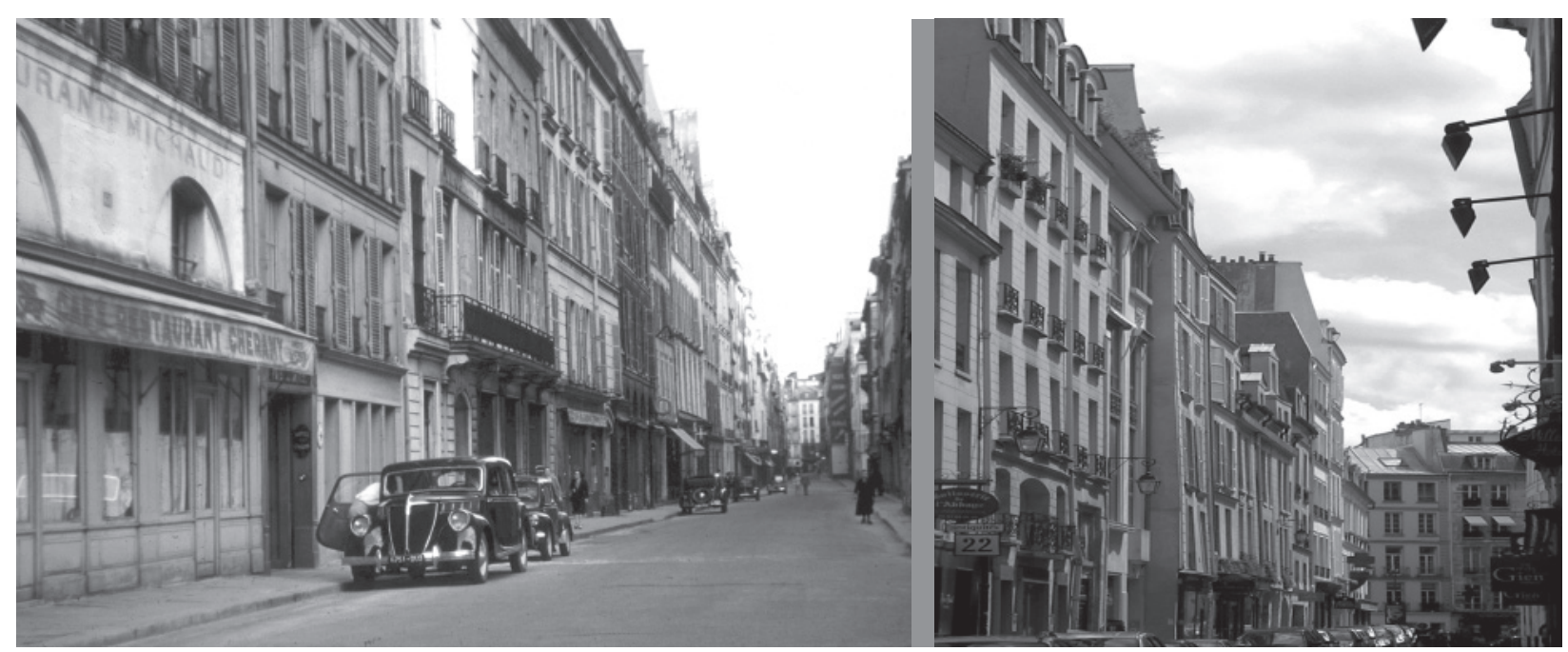

05 Dos imágenes de la rue Jacob: a la izquierda, el café-restaurante Cheramy (h. 1934); a la derecha, el edificio donde vivía Le Corbusier.

tomó su nombre del altar a Santiago elevado allí. En ella residieron personajes célebres: Wagner, Merimée, Colette o Hemingway. Sus edificios son de mediados del XVIII y comparten patios y traseras con Visconti, con tiendas de artesanos y grandes portones abiertos a patios adoquinados.

Entre los siglos XIX y XX, el destino de Jacob se vinculó a la prolongación de Rennes. Trazada para ligar la estación de Montparnasse al centro de París, quería Haussmann llevarla hasta el Sena para, cruzando el río, acceder al Louvre. Se habían comprado ya las casas entre Abbey y Beaux-Arts, y estaba hecha la numeración de las parcelas. Su traza cortaba la manzana Jacob-Visconti. Le Corbusier conocía bien las intenciones municipales respecto a su alojamiento ${ }^{14}$. Sólo la lentitud administrativa impidió la ejecución del proyecto.

Buscaba una casa en la zona, bien conocida de sus últimas estancias en París. Fue gracias a Charles Vildrac — poeta y dramaturgo, cuñado de Perret-, que vivía en el 20 de Jacob, por quien supo de la existencia ahí de un apartamento amansardado. Acogiéndose a los precios tasados por la Guerra y a su singularidad urbanística, lo alquiló en febrero de 1917 por sólo 500 francos mensuales ${ }^{15}$.

Era una amplia parcela de $1400 \mathrm{~m} 2$ donde Louvencourt había elevado una antigua casona Luís XV, cuyos jardines se extendían hasta Visconti. En ella se decía que había vivido Adrienne Lecouvreur, célebre artista, amante del mariscal de Saxe. Sobre esa parcela se situaron dos casas, una enfrentada a Jacob y otra a Visconti, con cuadras, cocheras y grandes viviendas exteriores, y con apartamentos menores en los pabellones de tres o cuatro pisos que articulaban el espacio interior, abriendo sus fachadas al jardín (Fig. 04). Desde 1850 la casa pertenecía a la familia Journault, a quien se la alquiló Le Corbusier por medio de Boucher \& Beaurain. Desde 1909 hasta su muerte, vivió ahí también Natalie Clifford Barney (1876-1972), que ocupó asimismo el pabellón situado al fondo del jardín: un pequeño templo clásico con la inscripción "À l'Amitié». En él tuvo su salón literario, uno de los más influyentes de Euro$\mathrm{pa}^{16}$. Más tarde poseyó la casa Michel Debré, ministro con De Gaulle, que la restauró hacia 1970.

\section{EL APARTAMENTO JACOB}

La vivienda en Jacob era un pequeño apartamento en la última planta del primer pabellón interior, con ventanas abiertas al este desde donde contemplar los árboles y el jardín. «Desde mi ventana — podía afirmar- no veo a mi alrededor más que un rico follaje y puedo decir, como Rollin, ruris et urbis incola sum, soy habitante de la ciudad y del campo, de los jardines silenciosos, ideales para trabajar» ${ }^{17}$.

El apartamento es representativo del hábitat de su tiempo, a la vez que emblemático del modo en que Le Corbusier entiende y vive un contenedor indiferenciado (Fig. 05).

En 1862, Goncourt había escrito: «La casa en París es como un individuo. El que se sirve de sus piernas, el comercio, está abajo; el que dirige, en el primero; el hom- 

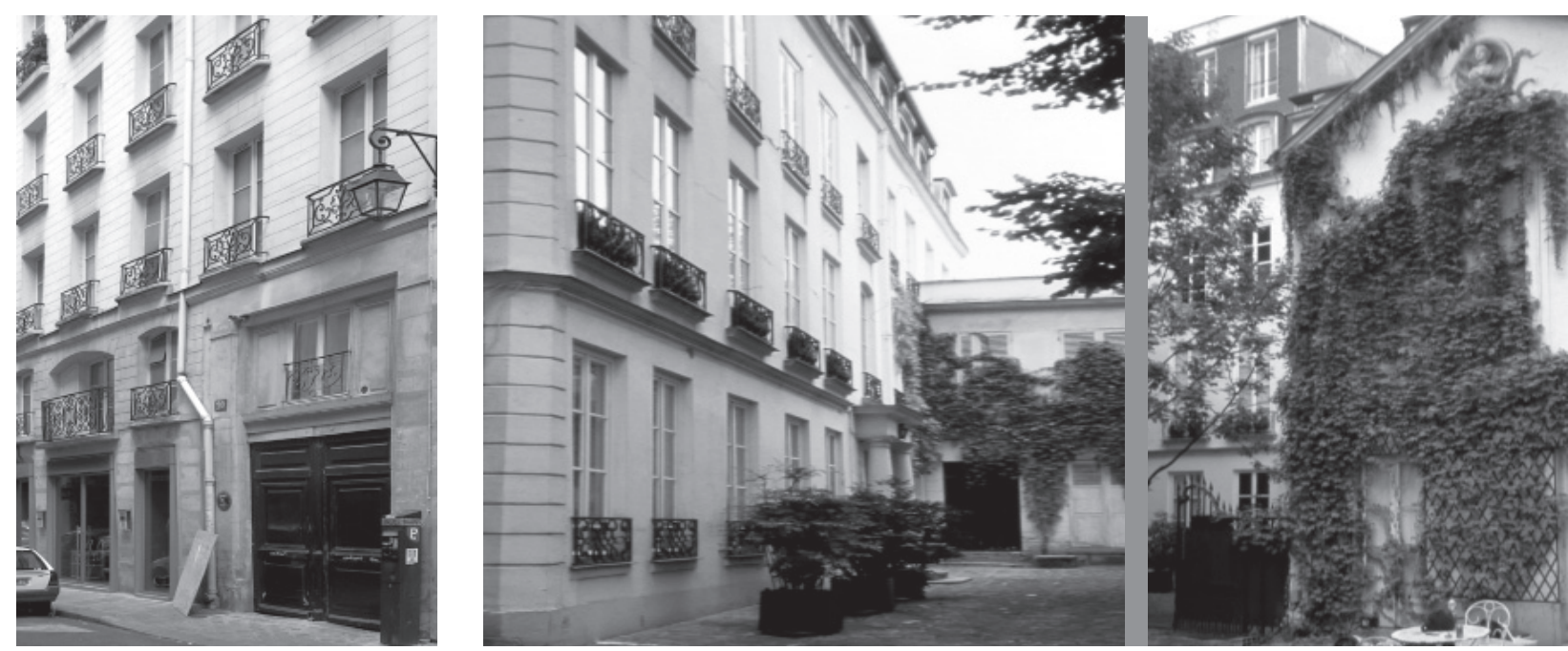

06 Portal de entrada al edificio.

$\mathbf{0 7}$ El patio delantero del edificio de apartamentos ocupado por Le Corbusier, y las ventanas de su 'maison-cachee'.

bre de letras se aloja arriba», añadiendo: «Al fondo de un patio, en Jacob, subiendo cinco pisos [está] la casa de un hombre de talento: de un critico en mansarda» ${ }^{18}$. Poco cambia esta descripción de Goncourt a Le Corbusier.

El apartamento Jacob era lo que habitualmente se denominaba un deuxpièces, un conjunto de dos estancias concatenadas, o sea, relacionadas de modo directo, sin pasillos intermedios de enlace, conjunto complementado o no - en Jacob sí- con un espacio de acceso y con sendos espacios de servicio para cocina y aseo. Era, pues, mucho más que una habitación de hotel o que un cuarto de criados, pero menos que un piso o apartamento convencional de los que por entonces se definirían como casas económicas o habitations à bon marché y à loyer moderé.

Si lo comparamos con sus hábitat anteriores en París, es bien distinto de la habitación del hotel económico en Écoles en 1908 o del hotel burgués en Quai Voltaire en 1916. Distinto, por supuesto, a la chambre d ami cedida por Du Bois en su vivienda del Trocadero. Pero también distinto del apartamento alquilado en 1908/09 en el Quai Saint Michel: una buhardilla frente a Nôtre-Dame, a medio camino entre atelier de artista y cuarto de sirvienta, cuyo espacio se reducía a un cubo habitado ${ }^{19}$.

Tanto en su primera versión amansardada como en la segunda - un espacio de configuración volumétrica ordinaria-, el apartamento Jacob pertenecía a ese tipo de hábitat particular que había surgido al final del Antiguo Régimen en algunas grandes capitales eu- ropeas como Roma o París, en que un espacio geométricamente simple y espacialmente sencillo servía para acoger una población variable de viajeros más o menos estables, en los barrios dieciochescos de Piazza de Spagna o de Saint Germain. Un hábitat que, sin dejar de ser antiguo, avanzaba ya cualidades propias del siglo XX: el hábitat de piezas indiferenciadas conectadas entre sí, que permitía tanto la independencia como la intercambiabilidad de las células, cuyo espacio anticipaba algunas características de las unidades del hábitat moderno, tan lejos del existenzminimun de las viviendas obreras como del diseño individualizado de las viviendas-atelier.

El apartamento Jacob podría describirse como un pequeño hábitat de casi $60 \mathrm{~m}^{2}$ elevado en la tercera planta - en la segunda luego- de un pequeño bloque interior a la parcela; un bloque que se articulaba por una escalera de pendiente tendida à la mansart, que distribuía dos viviendas similares a cada lado. Una, la septentrional, ocupaba el corazón mismo de esa parcela tan irregular que se abría en el medio de la manzana y permitía situarse en el centro del jardín (Fig. 06-07), facilitando a sus ocupantes sentirse - como Rollinhabitantes de la ciudad y del campo, con una visión rurbana que anticipaba los ideales que defenderá a escala metropolitana Le Corbusier para la Ville Radieuse.

\section{HÁBITAT Y HABITAR}

La permanencia en el recinto físico del hábitat, se hace variación frecuente en el habitar, durante los diecisiete años que Le Corbusier residió en Jacob. 

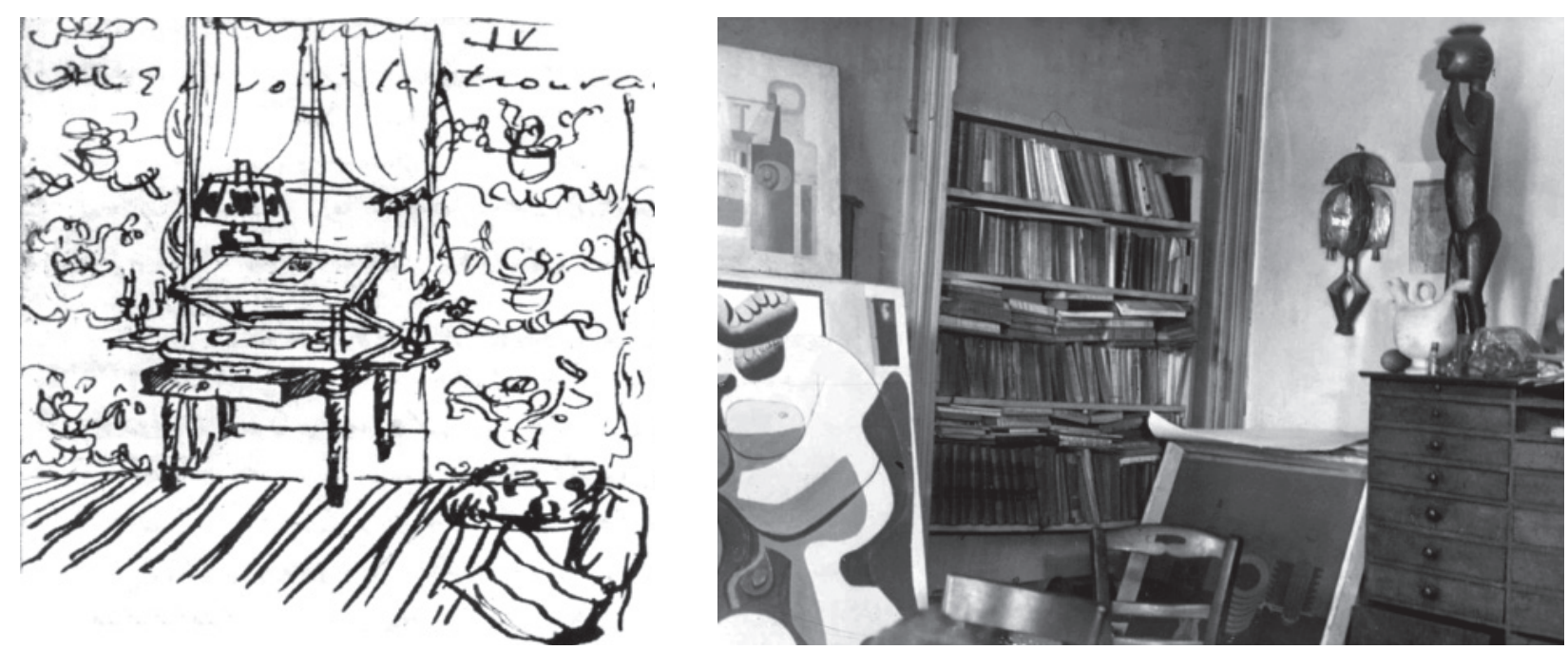

08 Le Corbusier, dibujo de su apartamento, h. 1917. 09 El atelier corbuseriano fotografiado hacia 1920

Podemos, en efecto, distinguir varias etapas distintas de ese habitar. Cuando, temporalmente quizás, alquila el apartamento. Cuando, enfrascado en los negocios, lo habita solo de noche, planteándose, incluso, cederlo y mudarse a la Rive Droite. Cuando, instalado en él su hermano, y trasladado al piso inferior, pasa a establecer una relación de equilibrio habitacional. Y, sobre todo, cuando aparece Yvonne que, instalada provisionalmente primero y luego de modo cada vez más estable en el apartamento, altera por completo su modo de vida: su habitar, en unos años felices, en que la valoración de ese hábitat es netamente positiva. Y, por último, en los años finales, cuando se plantea un hábitat nuevo y más amplio, que se confirma en Porte Molitor. A cada una de estas etapas vamos a dedicar una reflexión.

\section{EL APARTAMENTO Y EL HABITAR, 1917-1922}

En la primera el habitar es netamente provisional. Hay voluntad de fijarse definitivamente en París, aunque sin seguridad todavía en ello, y se busca un hábitat estable, a medio camino entre Quai Voltaire y Saint Germain, que supere la etapa de alojamientos temporales en casa de amigos o en establecimientos hoteleros. Como de costumbre, acude a Perret, y es Perret a través de Vildrac quien le consigue un alojamiento abuhardillado en su misma casa (cf. Fig. 01), creándose una vecindad que llega a hacerse familiar con Vildrac y su esposa, Rose Duhamel, de quien dice: «Es la vecina perfecta. La he adoptado como mamá en el extranjero. Es protectora, cálida, fuerte, activa». Le cuida la casa y le busca asistenta, «cara, pero (que) hace relucir mi apartamento como un foco de auto» ${ }^{20}$.
Establecido ya definitivamente desde octubre de 1917, lanza su vida a los negocios. Está entusiasmado con el apartamento y con sus leyendas, y así se lo cuenta a su familia y sus amigos de La Chaux, mostrándonos su momento más optimista. Las referencias son constantes. «Tres alfombras de rayas blancas y negras cubren el suelo. Numerosos cojines sirven de asiento con un enorme diván en la alcoba. Es un salón confortable, de intimidad completa. Rodeado de una absoluta tranquilidad en esta morada, sólo hay que esperar que se despierte la bella durmiente del bosque ${ }^{21}$, indica a su familia. «En el dormitorio, que es mi refugio — dice a un amigo-- un enorme diván bajo una profunda alcoba Luís XV, los muros empapelados en negro con conchas verdes, cestos de frutas y pájaros; los tapices cubren el fondo, cojines por el suelo y como único mueble, uno de esos maravillosos pupitres Tronchin de cajones profundos y un ingenioso mecanismo de

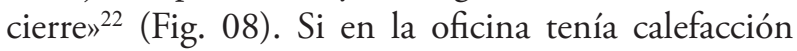
central, aquí dispone de un radiador a gas que funciona bien. Quiere seleccionar con cuidado los muebles, lo que no le es fácil ${ }^{23}$. Más tarde dirá: «Al principio estaba decorado con flores y molduras. Quise limpiar esas estupideces y blanquearlo de arriba abajo» ${ }^{24}$. Fue uno de los primeros signos del proceso artístico simplificador del periodo purista.

Las cosas varían poco después cuando, volcado en los negocios en la Rive Droite, le surgen las primeras dudas respecto a su alojar. No suele estar en el apartamento sino por la noche, confiesa en 1918 a sus padres ${ }^{25}$. Un año después, les dice: "Pienso conservar mi apartamento en Jacob (como) hôtelerie. Pues busco alojarme 

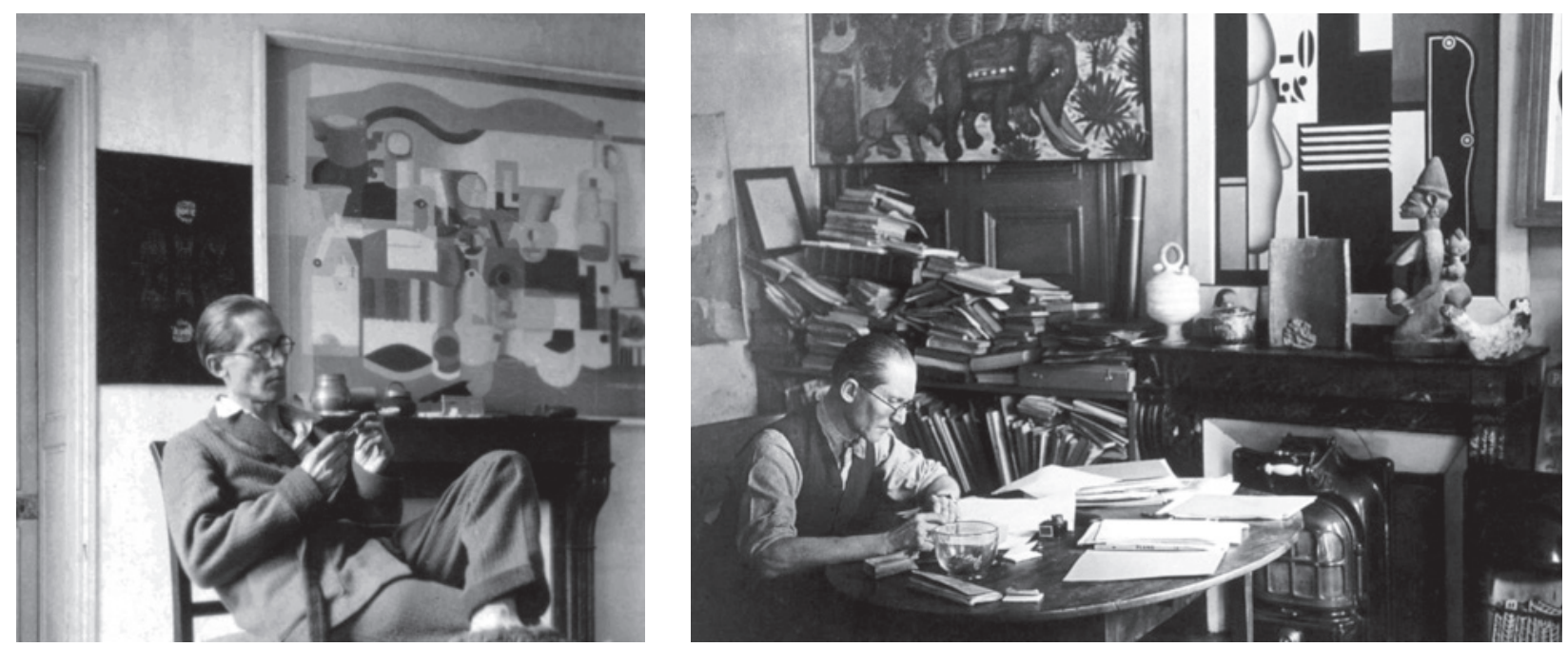

10 Le Corbusier en rue Jacob, h. 1920.

11 Le Corbusier en rue Jacob, fotografiado por Brassai hacia 1930.

cerca de mis negocios» ${ }^{26}$. Y en mayo, animando a su hermano a instalarse en París, dice: «Ya tienes un apartamento exquisito y prácticamente por casi nada aquí, en Jacob. Tú te quedarás con el apartamento. Yo me voy al centro, cerca de mis negocios, a la otra orilla ${ }^{27}$.

Animado por él, en septiembre de 1919 Albert deja La Chaux y se instala en París como profesor en la Schola Cantorum, antes de abrir una escuela propia. En diciembre, informa que está ya "completamente instalado en mi apartamento al que da un ambiente de claridad y de gusto, confort y reconfort apreciable, hasta inestimable» ${ }^{28}$. La instalación de Albert es el detonante de un cambio de actitud en la percepción del hábitat y en el habitar mismo.

A Albert le había dicho: «No cargues con cosas inútiles. Recuerda que los apartamentos parisienses son minúsculos, y un purista vive entre muros desnudos», indicándole que no trajera cama, pues «aquí se duerme sobre divanes ${ }^{29}$. Esta y otras indicaciones similares que aparecen en su correspondencia reflejan la sociedad y el París de la época.

Le Corbusier se reconcilia con Jacob gracias a Albert y, viendo la posibilidad de mejorar espacialmente el hábitat y el habitar, deja el espacio amansardado a su hermano y se traslada al piso inferior, con una disposición planimétrica similar, pero con mayor amplitud volumétrica y espacial. Es el hábitat Jacob donde —olvidada definitivamente la voluntad de migrar a la Rive Droite - vive en adelante, disfrutando de una urbs in ortu abierta al jardín interior, cuyas potencialidades vivideras anticipan el hábitat radieuse. "He tomado un apartamento en el piso de abajo, en la misma casa - escribe- Cedo el actual a Albert, que tiene gran suerte, porque encontrar hoy un apartamento en París es fabuloso" ${ }^{30}$. La crisis de alojamientos provoca el alza de los alquileres y la aparición de un mercado negro de vivienda que contribuyen a explicar su permanencia en Jacob. Éste apartamento del segundo piso constaba asimismo de un vestíbulo, una cocina y un aseo, $y$ dos piezas de estancia que se utilizaban como zona de noche y zona de día, ambas con suelo de madera barnizada. Usado a la vez como domicilio y como atelier íntimo, en él pinta sus telas puristas y escribe sus artículos y sus libros (Fig. 09-10).

En este nuevo hábitat se plantean —a un ritmo más calmado - otras fases diferenciadas de su habitar. En la primera, conviven piso arriba, piso abajo, los dos hermanos, ambos solteros, con una vida activa en el mundo de las artes y la cultura que tiene su emblema en la revista L'Esprit Nouveau, puesta en marcha esos años. Le Corbusier trabaja en Astorg, pinta y escribe en Jacob, y alterna en ambas orillas las relaciones sociales, teniendo como factor de estabilidad la presencia de Albert.

El matrimonio de éste con Lotti Raaf altera la situación. Inicialmente la pareja, con las hijas de Lotti, se instala en Jacob, aunque pronto busca un hábitat más amplio, encargando a Le Corbusier la construcción de una vivienda propia, que se ubicará en Jasmin. Esta mudanza altera para siempre la relación de intimidad con su hermano y altera el habitar en Jacob. Ello ocu- 
rre casi al tiempo en que cambia su situación personal tras conocer a Yvonne.

\section{EL APARTAMENTO Y EL HABITAR, 1922-1934}

Desde el verano de 1922 —al tiempo de la Ville Contemporaine-, comparte su domicilio con ella, cuya presencia se iría consolidando en su vida. Convertido en un hábitat dual exterior-interior, el binomio formado por Jacob y Saint Germain, es desde entonces no sólo el refugio doméstico sino también el centro de su vida social cotidiana.

Esta cohabitación cambia para siempre el habitar en Jacob. La presencia física de Yvonne y sus necesidades espaciales alteran irremisiblemente el modo de vivir el apartamento. Se intenta primero sostener un habitar similar, compartiendo la zona de noche e intentando compartir también los usos diferenciados de la zona de día. Pero la situación se ve dificultada cada día que pasa y que la presencia de Yvonne se hace más estable. Aunque su vida social se desarrolla preferentemente al exterior, en las calles y cafés del barrio, la ocupación de la zona de día altera los usos espaciales del apartamento. Es el tiempo del logis roulotte al que se refiere en sus últimos ańos, en conversaciones con Petit. De la leonera o el capharnaum de Jacob, como también lo llama $^{31}$. En otoño de 1924 suprime definitivamente la dualidad Rive Droite-Rive Gauche, trasladando su estudio de Astorg a Sèvres. A partir de entonces, habita y tiene su atelier íntimo en Jacob, y trabaja y tiene su estudio profesional público en Sèvres, a diez minutos de paseo uno de otro ${ }^{32}$.

Sus puntos de encuentro con sus amigos son el restaurante Cheramy (cf. Fig. 03), donde Vildrac y los Duhamel son contertulios habituales, el Petit-SaintBenoit, frecuentado por Chagall o Cocteau, o el Deux-Magots donde coincide con Gide, Gallimard o Breton. Trasladados a Molitor, Yvonne echó siempre de menos ese mundo de Jacob y Saint Germain ${ }^{33}$.

Jacob es no sólo el refugio doméstico sino también el atelier personal, el lugar de las búsquedas plásticas, poéticas y literarias: el atelier del pensamiento y la pintura, externalizada ésta — tras la llegada de Yvonne- al domicilio de Pierre, que desde 1920 habitaba también en la Rive Gauche, en un apartamento amueblado de la rue de Seine —alquilado a nombre de L'Esprit Nouveau-, compuesto por una pieza a calle, una antecámara y una pieza a patio ${ }^{34}$. En este apartamento se refugiaría Le Corbusier a pintar durante bastantes años.
Su jornada, pues, se centra en la Rive Gauche, pero se fragmenta en tres ámbitos diferenciados: Jacob, Sèvres y Seine. Esta situación la valora de modo optimista en los primeros años con Yvonne, como todo hombre enamorado. Valora positivamente un habitar que no varía espacialmente, pero que se va reconvirtiendo poco a poco en hogar familiar. Aún en otoño de 1930 se refiere con cariño Le Corbusier a «mi pequeña boîte de Jacob», modesta al lado de la casa de su madre o de Albert. «En nuestros dos cuartos acumulo gran trabajo: escribo mis libros, preparo mis cuadros ${ }^{35}$ (Fig. 11).

Esa reconversión, sin embargo, provoca la mutación definitiva. Muerto su padre, se plantea poco a poco regularizar la situación con Yvonne a través del matrimonio. Dudas primero, excusas luego so pretexto de la nacionalización francesa, conseguida ésta, se casan en diciembre de 1930. La nueva situación legal y social tranquiliza a Yvonne pero, por el contrario, reclama para Le Corbusier una nueva situación física y una nueva situación espacial.

Surge entonces la posibilidad y el proyecto de un hábitat nuevo, en condiciones de Ville Radieuse, junto a Porte Molitor y Boulogne, a quince minutos escasos de la casa de Lotti y Albert en Jasmin. La idea es buena, aunque suponga abandonar el hábitat familiar y social de Saint Germain. A medida que avanzan el proyecto y las obras, Le Corbusier - como tantas otras veces hizo - irá olvidando y aun aborreciendo la etapa anterior - Jacob en este caso-, hasta el punto de que en el momento de irse sólo parece mantener con Jacob una relación negativa, contrastando esos «años de pesadilla sombría de Jacob donde hemos vivido apilados, 17 años yo, 12 años ella», con «las nuevas condiciones milagrosas» de una vivienda «donde todo es cielo y luz, espacio y simplicidad $»^{36}$. Era menester quizá que Jacob menguara para que Molitor pudiera brillar con más esplendor.

Son, pues, varios los habitares en el hábitat común de Jacob, pero es este último el que ha prevalecido en la memoria y en la valoración corbuseriana. En Molitor el hábitat querrá coincidir ya definitivamente con el habitar y proyectarse ambos desde la arquitectura y desde los ideales — por entonces en su apogeo- de la Ville Radieuse. «El apartamento Molitor — diráestá en condiciones de Ville Radieuse» ${ }^{37}$.

\section{CONCLUSIÓN}

Tras diecisiete años en Jacob, en la primavera de 1934 Le Corbusier pasa a Porte Molitor, a un apartamen- 
to-atelier bajocubierta: una villa individual sobre un edificio colectivo. Considerado como el hábitat corbuseriano por excelencia, Molitor ha oscurecido el lugar donde Jeanneret se transformó en Le Corbusier y donde vivió 17 fecundos años, haciendo de Jacob un hábitat desconocido: una maison cachée.

Tanto mediante el texto como mediante las imágenes - enfrentadas en esa lectura paralela de la que tanto gustaba Le Corbusier- esta monografía ha analizado esta casa escondida en su doble aspecto del hábitat y del habitar. Ha descubierto el lugar y el espacio — no sólo interior sino también exterior, social y urbano- donde Le Corbusier vivía, y ha explicado sus distintos mo- dos de habitar a través del tiempo, mostrando cuánto la maison cachée y la urbs in ortu tienen de antecedentes del hábitat radieuse.

Mediante la fotografía, Brassaï analizó esta maison cachée corbuseriana en los momentos finales, observando cómo estaba todo tan sobrecargado de objetos, libros y papeles que no quedaba más que un pequeño sitio para escribir o dibujar ${ }^{38}$. Es el penúltimo testimonio del habitar y del hábitat en Jacob. El último es la imagen que el propio Le Corbusier dibuja de sí mismo, de espaldas, como despidiéndose, antes de abandonar Jacob ${ }^{39}$ (Fig. 12). «Se pasa una pagina escribe- . Termina un ciclo» ${ }^{40}$.

12 Le Corbusier en rue Jacob, dibujado por él mismo, h. 1934.

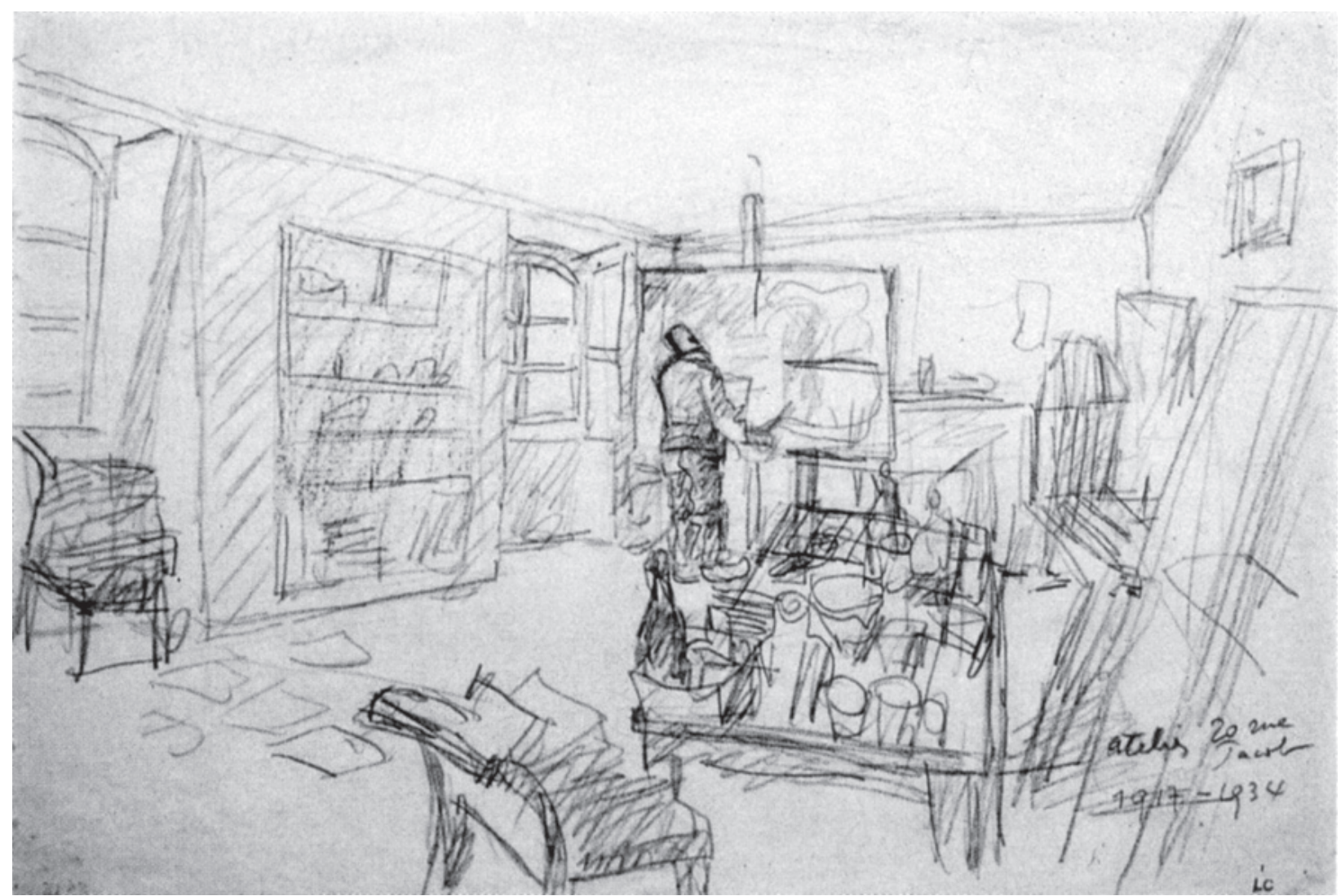




\section{Notas}

1. Las principales y casi únicas referencias a dicho hábitat se encuentran en Jean Petit, Le Corbusier lui même (Zurich: Rousseau, 1970) y en Robert Doisneau y Jean Petit, Bonjour Monsieur Le Corbusier (París: Grieshaber, 1988). Recientemente, pero con distinto enfoque, a Jacob se ha referido Jorge Tárrago Mingo, «20 rue Jacob: Le Corbusier, las fotografías de Brassäi y Ms. Barney», RA Revista de Arquitectura 11 (2009): 37-50.

2. Cf. José Ramón Alonso Pereira, «Le Corbusier y París: percepciones y descubrimientos», Massilia (2008): 32-43.

3. Marie-Jeanne Dumont, Le Corbusier, l'éléve et ses maîtres, (I) Lettres à Auguste Perret (París: Linteau, 2002), carta 14 marzo 1912.

4. Cf. H. Allen Brooks, Le Corbusier's formative years (Chicago: University of Chicago, 1997).

5. Ibídem. Véase asimismo Michel Borjon (ed.), Le Quai Voltaire, (París: Action Artistique, 1990).

6. FLC, GEJ, 6 octubre 1917. Ese año y sus viajes pueden seguirse en el diario de su padre, depositado en la Fundación.

7. FLC, correspondencia con Albert, 22 octubre 1917.

8. FLC, correspondencia con sus padres, 9 enero 1919.

9. FLC, correspondencia con Albert, 6 mayo 1919.

10. Cf. José Ramón Alonso Pereira, «35 rue de Sèvres, Le Corbusier y sus contextos», en Le Corbusier, mise au point (Valencia: Memorias Culturales, 2012): 50-71.

11. Léon-Paul Farge, Le pieton de Paris (1932-39) (París: Gallimard, 1982). Cf. asimismo Armand Lanoux, Paris 1925 (París: Delpire, 1957) y Jean Paul Caracalla, Saint-Germain-des-Près (París: Flammarion, 1993).

12. Cf. Jean Petit, Le Corbusier lui même (Zurich: Rousseau, 1970), y Robert Doisneau y Jean Petit, Bonjour Monsieur Le Corbusier (París: Grieshaber, 1988).

13. Pierre Champion, Mon vieux quartier (París, Gallimard, 1932), 53.

14. Los servicios de la Prefectura daban el plano del trazado previsto y de los inmuebles ya adquiridos por el municipio.

15. Cf. FLC, E.1.9.133 y siguientes. Conviene asimismo recordar que los sótanos del edificio habían sido declarados refugio antiaéreo durante la Guerra. 16. Cf. Jean Chalon, Chère Natalie Barney (París: Flammarion, 1992), y Tárrago, «20 rue Jacob».

17. Champion, Mon vieux quartier, 54.

18. Edmond de Goncourt, Journal, memoires de la vie littéraire (1862) (París: Charpentier, 1987).

19. Cf. Alonso, «20 rue Jacob».

20. FLC, correspondencia con sus padres, 22 noviembre 1917.

21. Loc. cit.

22. FLC, correspondencia con Humbert, 4 marzo 1918.

23. En octubre de 1919, tras la venta de la Maison Jeanneret, Albert y Édouard pidieron a sus padres el envío de sus muebles, su piano y sus enseres domésticos.

24. FLC, correspondencia con Ritter, 22 octubre 1919.

25. Cf. FLC, correspondencia con sus padres, 17 febrero 1918.

26. FLC, correspondencia con sus padres, 9 enero 1919.

27. FLC, correspondencia con Albert, 6 mayo 1919.

28. FLC, correspondencia con sus padres, 2 diciembre 1919.

29. FLC, correspondencia con Albert, 12 y 22 septiembre 1919.

30. FLC, correspondencia con sus padres, 2 y 7 octubre 1919.

31. Cf. Petit, Le Corbusier lui même.

32. Cf. Alonso, «20 rue Jacob».

33. Cf. Petit, Le Corbusier lui même.

34. Cf. FLC, A.1.3.341.350, marzo 1921. Tras el traslado a Molitor, Pierre Jeanneret ocupará el apartamento Jacob.

35. FLC, correspondencia con su madre, 28 septiembre 1930.

36. FLC, correspondencia con su madre, 28 mayo 1934.

37. FLC, correspondencia con su madre, 29 abril 1934.

38. Cf. Brassaï, Les artistes de ma vie (París: Denoël, 1982); Tárrago, «20 rue Jacob»; y archivo fotográfico FLC.

39. Cf. FLC, L.4.12.1-22.

40. FLC, correspondencia con su madre, 29 abril 1934.

\section{Procedencia de las ilustraciones}

Fig. 01. Archivo FLC-L.4-01-10.

Fig. 02 y 04 . Bing Maps.

Fig. 03. Fotografía y archivo del autor.

Fig. 05. Archivo del autor.

Fig. 06 y 07. Fotografías del autor.

Fig. 08. Archivo FLC-R.1.10, 05.12.17.

Fig. 09. Archivo FLC-L.4-12-20.

Fig. 10. Archivo FLC-L.4-12-22.

Fig. 11. Archivo FLC-L.4-12-01.

Fig. 12. Archivo FLC-A.3-16-52.

\section{Sobre el autor}

Catedrático de Historia de la Arquitectura y del Urbanismo en la Universidade da Coruña. Entre sus obras destacan los libros: Madrid 1898-1931, de corte a metrópoli (1985), Historia General de la Arquitectura en Asturias (1996), La Ciudad Lineal de Madrid (1998), Ingleses y españoles, la arquitectura de la Edad de Plata (2000), Roma Capital, invención y construcción de la ciudad moderna (2003), Utopía y deconstrucción en la arquitectura contemporánea (2003), e Introducción a la Historia de la Arquitectura ( $4^{a}$ ed. 2012). Ha sido pensionado en la Academia de Espańa en Roma y en la Fondation Le Corbusier y el College d'Espagne en París. Ha impartido cursos y conferencias en centros universitarios de Espańa, Italia, Francia, Reino Unido, Argentina, Méjico, Cuba y Estados Unidos.

jralonso@udc.es 